\title{
Optimalisasi Penjadwalan Mata Kuliah Menggunakan Teori Pewarnaan Graf
}

\author{
A. Muhajir Nasir ${ }^{1}$, Faisal2 ${ }^{2}$, Dedy Setyawan ${ }^{3}$ \\ Pendidikan Matematika, FKIP Universitas Muslim Maros ${ }^{1,3}$ \\ amuhajirnasir@umma.ac.id ${ }^{1}$, faisalmipa@gmail.com², dedynuny50@gmail.com³
}

\begin{abstract}
Abstrak. Penelitian ini merupakan penelitian terapan yang bertujuan untuk mengoptimalkan sistem penjadwalan mata kuliah pada program studi Pendidikan Matematika FKIP Universitas Muslim Maros tahun akademik 2020/2021 menggunakan teori pewarnaan graf Welch-Powell. Sumber data pada penelitian ini adalah kartu rencana studi setiap tingkat mahasiswa program studi Pendidikan Matematika FKIP Universitas Muslim Maros semester genap tahun akademik 2020/2021, 14 dosen pengampuh mata kuliah, 17 ruang kuliah dan slot waktu yang tersedia untuk proses perkuliahan. Data penelitian ini diolah dan dianalisis dengan teori pewarnaan graf algoritma Welch-Powell, mata kuliah dimisalkan sebagai simpul-simpul graf dan hubungan antara mata kuliah tersebut dimisalkan sebagai sisi. Pewarnaan berdasarkan dari simpul berderajat tertinggi dan simpul-simpul yang bertetangga diberi warna yang berbeda. Simpul yang berwarna sama merupakan mata kuliah yang dapat diadakan secara bersamaan dan banyaknya warna yang dihasilkan menunjukkan banyaknya sesi perkuliahan yang dibutuhkan. Dengan penerapan teori pewarnaan graf dengan algoritma Welch-Powell dihasilkan jadwal perkuliahan yang optimal tanpa adanya bentrok antar mata kuliah.
\end{abstract}

\section{Kata Kunci: Jadwal perkuliahan, Pewarnaan Graf, Algoritma Welch-Powell}

\begin{abstract}
This research is an applied research that aims to optimize the system of scheduling courses in the study program of University Moeslim Maros 2020/2021 academic year using the theory of Welch-Powell graph coloring. The data sources in this study plan cards for each level of students of the Study Program mathematics education of University Moeslim Maros even semester of 2020/2021 academic year, 14 lecturersof lectures, 14 lecture halls and time slots avaible for the lecture. The data of this study were processed and analyzed using Welch-Powell algorithm graph coloring theory, the subjects is assumed to be graph nodes and the relationship betwen subjects to be a vertex. Coloring based on the verticesof the highest degree and neightboring nodes are given different colors. The same colored node is course that can be held simultaneously and the number of colors produced shows the number of lecture sessions needed. By applying graph coloring theory with Welch-Powell algorithm, optimal lecture schedules are produced without any clashes betwen subjects.
\end{abstract}

\section{Keywords: Lecture Schedule, Graph Coloring, Welch-Powell Algorithm}

\section{A. Pendahuluan}

Graf merupakan salah satu cabang ilmu khususnya matematika terapan. Graf sebenarnya sudah dikenal sejak tahun 1836, yaitu ketika graf digunakan pertama kali oleh ahli matematika asal Swiss. Masalah yang sering kali muncul di tengah-tengah kehidupan masyarakat Leonardo Euler, untuk menyelesaikan jembatan Konigsberg. Graf telah memberikan banyak peran dalam perkembangan matematika terapan, karena graf dapat diaplikasikan dalam kehidupan seharihari. Dalam kehidupan sehari-hari banyak permasalahan yang memerlukan solusi (Purwanto, 2010). Seringkali membutuhkan solusi dari disiplin ilmu, dengan bantuan bahasa lambang pada matematika, permasalahan tersebut lebih muda untuk dipahami, lebih mudah dipecahkan atau bahkan dapat ditunjukkan bahwa suatu persoalan tidak mempunyai solusi.

Matematika merupakan alat untuk menyederhanakan penyajian dan pemahaman masalah. Dalam bahasa matematika, suatu masalah dapat menjadi lebih sederhana untuk disajikan, dipahami, dianalisis dan dipecahkan. Untuk keperluan tersebut, pertama dicari pokok masalahnya, kemudian dicari rumusan atau model matematikanya. Matematika diskrit adalah cabang matematika yang mengkaji tentang objek-objek secara diskrit. Diskrit artinya terdiri dari elemen-elemen yang sejenis, yang berbeda atau tidak terhubung (Munir, 2014). Dalam 
matematika diskrit sendiri mempunyai cabang, diantaranya: himpunan, relasi dan fungsi, induksi matematika, kombinatorial, aljabar Boolean, kompleksitas algoritma dan graf. Pada intinya matematika diskrit mempelajari tentang kombinatorial dan teori graf.

Teori graf adalah salah satu cabang ilmu matematika. Teori graf merupakan suatu pokok bahasan yang mendapat banyak perhatian karena model-modelnya sangat berguna untuk diaplikasikan dalam kehidupan sehari-hari, diantaranya adalah digunakan dalam jaringan komunikasi, transportasi, ilmu komputer, riset operasi dan masih banyak aplikasi lainnya. Graf dipakai diberbagai disiplin ilmu maupun dalam kehidupan sehari-hari. Penggunaan graf diberbagai bidang tersebut adalah untuk memodelkan persoalan. Untuk menyelesaikan permasalahan tersebut digunakan rumusan atau model teori grafnya, sehingga permsalahan akan menjadi jelas dan mudah menganalisisnya. Menurut catatan sejarah, graf diperkenalkan seorang ahli matematika dari Swiss yaitu Leonardo Euler pada tahun 1736. Beliau berhasil menyelesaikan permasalahan jembatan Konigsberg dengan menggunakan graf. Secara matematis, graf didefinisikan sebagai pasangan himpunan $(\mathrm{V}, \mathrm{E})$, yang dalam hal ini $\mathrm{V}$ melambangkan himpunan tidak kosong dari tititk-titik yang dapat ditulis $\mathrm{V}=\left\{\mathrm{v}_{1}, \mathrm{v}_{2}, \ldots \mathrm{v}_{\mathrm{n}}\right\}$ dan $\mathrm{E}$ melambangkan himpunan sisi yang menghubungkan titik yang dapat ditulis $E=\left\{\mathrm{e}_{1}, \mathrm{e}_{2}, \ldots \mathrm{e}_{\mathrm{n}}\right\}$. Graf digunakan untuk merepresentasikan objek-objek diskrit dan hubungan antara objek-objek tersebut (Wijaya, 2009). Dengan demikian dinyatakan bahwa V tidak boleh kosong, sedangkan E boleh kosong. Jadi, sebuah graf dimungkinkan tidak mempunyai sisi satupun, tetapi titiknya harus ada minimal satu yang dapat disebut sebagai graf kosong. Sedangkan jika sebuah graf yang mempunyai sisi minimal satu dan mempunyai titik minimal dua dapat disebut graf tak kosong.

Pada kesempatan ini, penulis membahas mengenai pengoptimalan penjadwalan mata kuliah menggunakan teori pewarnaan graf. Masalah pewarnaan di dalam graf memiliki banyak variasi dengan tipe yang berbeda. Ada bilangan kromatik dan pewarnaan dengan algoritma Welch-Powell (permasalahan pewarnaan titik). Banyak persoalan yang mempunyai karakteristik seperti pewarnaan graf sehingga membuat pewarnaan pada graf ini menarik untuk dikaji lebih dalam. Misalnya dalam penyusunan jadwal perkuliahan sehingga semua tingkatan mahasiswa dapat mengikuti setiap mata kuliah yang diprogramkannya tanpa ada jadwal yang bertabrakan antara satu matakuliah dengan mata kuliah lainnya.

Penyusunan jadwal perkuliahan menjadi bagian penting dari kegiatan yang rutin dilakukan setiap semester pada sebuah perguruan tinggi. Penjadwalan perkuliahan merupakan suatu cara mengalokasikan mahasiswa yang mengambil mata kuliah, dosen yang mengampu mata kuliah dan ruang yang digunakan untuk perkuliahan pada slot waktu yang tersedia. Kegiatan perkuliahan dilakukan dengan mempertimbangkan jumlah dosen, ruang kelas dan slot waktu yang tersedia. Seringkali pada proses penyusunan jadwal perkuliahan terjadi konflik atau bentrok mata kuliah/dosen/ruang kuliah pada suatu slot waktu tertentu, hal ini dapat disebabkan karena:

1. Adanya kesamaan dosen pengajar pada mata kuliah yang berbeda

2. Adanya penggunaan ruangan yang sama untuk mata kuliah yang berbeda

3. Adanya keterbatasan jumlah ruang kuliah yang tersedia

4. Adanya kebutuhan ruangan tertentu (khusus) untuk beberapa mata kuliah

5. Adanya permintaan dosen yang bersangkutan untuk tidak mengajar pada slot waktu tertentu.

Penyusunan jadwal perkuliahan yang kurang efisisen seringkali terjadi di program studi Pendidikan Matematika FKIP Universitas Muslim Maros setiap semesternya, karena masih menghadapi kendala terjadinya bentrok dan belum terpenuhinya permintaan dosen untuk tidak dijadwalkan pada slot waktu tertentu. Penyusunan jadwal yang dilakukan dengan menempatkan mata kuliah tertentu pada suatu ruang dan slot waktu tertentu, selanjutnya untuk mata kuliah yang lain dengan mencari slot-slot waktu yang masih kosong seperti ini terasa belum optimal. 
Sehingga untuk peningkatan mutu pelayanan akademik di Universitas perlu dicari solusi agar masalah-masalah seperti diatas tidak terulang lagi, yang tentunya sangat merugikan mahasiswa dan dosen.

Salah satu cara yang untuk mengoptimalkan penjadwalan mata kuliah adalah dengan menerapkan metode-metode penjadwalan yang telah dikembangkan sebelumnya. Beberapa metode penjadwalan yang banyak digunakan untuk persoalan University Timetable Problem (UTP) antara lain penggunaan metode berbasis populasi (Sabar et al., 2012; Saragih et al., 2012), metode heuristic (Buliali et al., 2008; Jat \& Yang, 2008; Kohshori \& Abadeh, 2012; Puspaningrum et al., 2013; Setemen, 2010; Siswono \& Palgunadi, 2014; Yudihartanti et al., 2011), metode pewarnaan graf (Al-Mouhamed \& Dandashi, 2010; Astuti, 2011; Bozyer et al., 2011; Dewi, 2014; Hiryanto \& Thio, 2011; Lumbantoruan, 2014; Malkawi et al., 2008; Sabar et al., 2009; Setiawati et al., 2015; Susiloputro et al., 2012; Tasari, 2012).

Pada penelitian ini akan digunakan metode pewarnaan graf karena dianggap lebih sederhana dibanding metode yang lain, yaitu dengan menempatkan kejadian setiap kejadian secara sekuensial ke dalam periode waktu yang valid sedemikian sehingga tidak ada konflik antar kejadian. Teknik ini menggunakan refresentasi graf, dimana kejadian direpresentasikan sebagai verteks (titik) dan konflik direpresentasikan sebagai jalur/simpul (Li et al., 2012). Dan hasil telaah literatur menunjukkan algoritma yang sering digunakan dalam pewarnaan graf adalah Welch-Powell algorithm (Astuti, 2011; Hiryanto \& Thio, 2011; Susiloputro et al., 2012). Dalam sebuah penelitian yang dilaksanakan pada tahun 2017 di Universitas Katolik Musi Charitas yang dibiayai oleh Direktorat Penelitian dan Pengabdian Masyarakat, Direktorat Jendral Pendidikan Tinggi menunjukkan bahwa pewarnaan graf dengan Welch-Powell dapat menghasilkan jadwal yang optimal (Sunarni et al., 2018). Berdasarkan identifikasi beberapa masalah yang telah diuraikan di atas, maka peneliti melakukan penelitian yang berkaitan dengan penyusunan jadwal perkuliahan dengan mengaplikasikan teori pewarnaan graf yang dikembangkan oleh Welch-Powell.

\section{B. Metodologi Penelitian \\ 1. Jenis Penelitian}

Jenis penelitian yang digunakan adalah Penelitian Terapan. Penelitian ini dimulai dengan mengumpulkan segala data yang diperlukan untuk diterapkan pada teori-teori yang akan dikonstruksi dalam hal ini teori pewarnaan graf dengan metode welch-powell, selanjutnya data tersebut disajikan ke dalam bentuk tabel yang memuat keterhubungan antar data-data tersebut. Kemudian dengan teori pewarnaan graf welch-powell data tersebut akan diolah dan dianalisis sehingga akhirnya akan dihasilkan teknik penjadwalan yang optimal.

\section{Subjek Penelitian}

Subjek dalam penelitian ini adalah 31 mata kuliah yang diprogramkan masing-masing tingkatan mahasiswa dan 14 dosen pengampuh mata kuliah di program studi Pendidikan Matematika FKIP Universitas Muslim Maros pada semester genap tahun akademik 2020/2021 serta slot waktu dan 17 ruangan yang tersedia.

\section{Prosedur Penelitian}

Tahapan yang akan dilakukan pada penelitian ini adalah sebagai berikut:

a) Pendalaman studi literatur

b) Identifikasi kebutuhan sistem

c) Analisis dan pemodelan sistem penjadwalan

d) Desain sistem penjadwalan

e) Penjadwalan sistem

Berdasarkan studi literatur dan hasil identifikasi kebutuhan sistem, dipilih metode pewarnaan graf menggunakan algoritma welch-powell. Tahapan dalam penjadwalan dimulai 
dari mengidentifikasi hubungan antar verteks dalam hal ini mata kuliah, berdasarkan kesamaaan dosen pengampu dan semester. Hubungan yang terbentuk menjadi dasar dalam perhitungan derajat mata kuliah yang digunakan dalam pewarnaan graf. Berikutnya hasil pewarnaan menjadi dasar dalam pengalokasian slot waktu dan ruang pada jadwal.

\section{Teknik Pengumpulan Data}

Sumber data dari penelitian ini adalah hasil dari kartu rencana studi mahasiswa program studi Pendidikan Matematika FKIP Universitas Muslim Maros semester genap tahun akademik 2020/2021, dosen pengampuh mata kuliah, ruangan yang tersedia dan slot waktu yang akan digunakan dalam proses perkuliahan.

\section{Teknik Analisis Data}

Pada penelitian ini membahas pewarnaan elemen graf dengan menggunakan algoritma welch-powell. Algoritma welch-powell merupakan salah satu algoritma pewarnaan graf yang melakukan pewarnaan berdasarkan derajat tertinggi dari simpul-simpulnya, disebut Largest Degree Ordering (LDO). Algoritma welch-powell dapat digunakan untuk mewarnai sebuah graf $\mathrm{G}$ secara efisien dan praktis, walaupun tidak selalu memberikan jumlah warna minimum yang diperlukan untuk mewarnai G. Adapun tahapan pewarnaan dengan algoritma welchpowell adalah sebagai berikut :

a. Urutkan simpul-simpul dari G dalam derajat yang menurun

b. Gunakan satu warna untuk mewarnai simpul pertama (yang mempunyai derajat tertinggi) dan simpul-simpul lain (dalam urutan yang terurut) yang tidak bertetangga dengan simpul yang pertama ini.

c. Mulai lagi dengan simpul yang berderajat tertinggi berikutnya di dalam daftar terurut yang belum diwarnai dan ulangi proses pewarnaan simpul dengan menggunakan warna kedua.

d. Ulangi penggunaan warna-warna sampai semua simpul telah diwarnai.

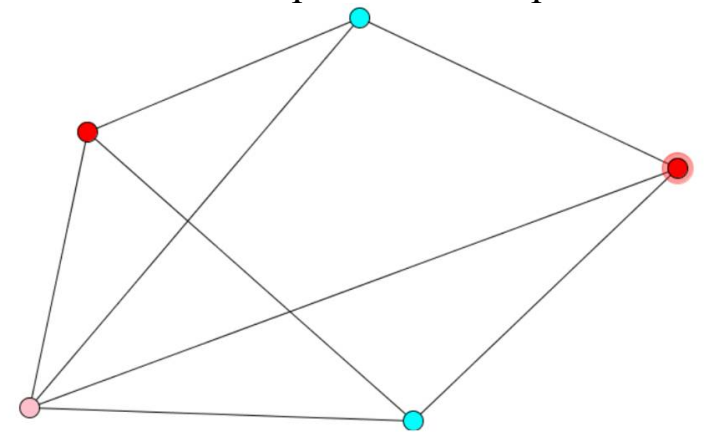

Gambar 1. Contoh Pewarnaan Simpul dengan Algrotma Welch-Powell

Dari penjelasan diatas dapat dibuat simulasi penjadwalan sederhana menggunakan teori pewarnaan graf tesebut. Misalkan terdapat delapan orang mahasiswa $(1,2, \ldots, 8)$ dan lima buah matakuliah yang dapat dipilihnya $(A, B, C, D, E)$. Tabel berikut memperlihatkan matriks lima mata kuliah dan delapan orang mahasiswa. Angka 1 pada elemen $(i, j)$ berarti mahasiswa $i$ memilih mata kuliah $j$, sedangkan angka 0 menyatakan mahasiswa $i$ tidak memilih mata kuliah $j$.

Tabel 1. Distribusi Mata Kuliah yang Diprogramkan Tiap Mahasiswa

\begin{tabular}{cccccc}
\multirow{2}{*}{ Mahasiswa } & \multicolumn{5}{c}{ Mata Kuliah } \\
\cline { 2 - 6 } & A & B & C & D & E \\
\hline 1 & 0 & 1 & 0 & 0 & 1 \\
\hline 2 & 0 & 1 & 0 & 1 & 0 \\
\hline
\end{tabular}




\begin{tabular}{cccccc}
\multirow{2}{*}{ Mahasiswa } & \multicolumn{5}{c}{ Mata Kuliah } \\
\cline { 2 - 6 } & A & B & C & D & E \\
\hline 3 & 0 & 0 & 1 & 1 & 0 \\
\hline 4 & 1 & 1 & 0 & 0 & 0 \\
\hline 5 & 0 & 1 & 0 & 1 & 0 \\
\hline 6 & 0 & 0 & 1 & 1 & 0 \\
\hline 7 & 1 & 0 & 1 & 0 & 0 \\
\hline 8 & 0 & 0 & 1 & 1 & 0 \\
\hline
\end{tabular}

Selanjutnya akan dicarikan solusi mengenai jumlah hari paling sedikit yang dibutuhkan untuk jadwal ujian tersebut sedemikian sehingga semua mahasiswa dapat mengikuti ujian mata kuliah yang diambilnya tanpa bertabrakan waktunya dengan jadwal ujian kuliah lain yang juga diambilnya, yaitu dengan memisalkan simpul sebagai mata kuliah dan sisi sebagai mahasiswa yang mengambil kedua mata kuliah (dua simpul). Perhatikan gambar berikut:

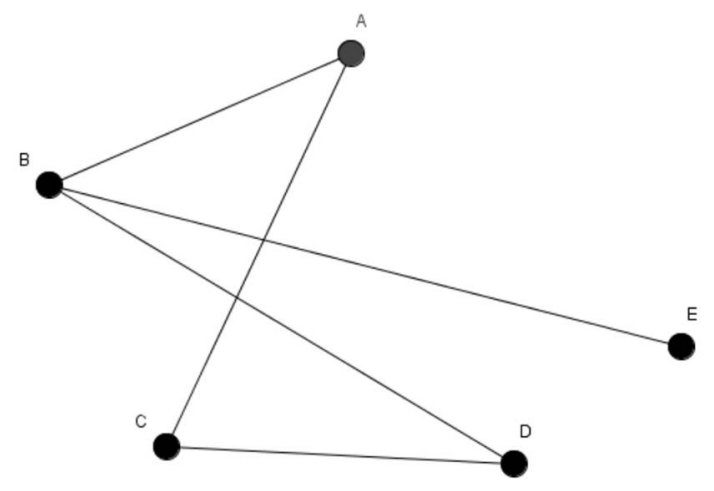

Gambar 2. Graf Penjadwalan Ujian 5 Mata Kuliah untuk 8 Orang Mahasiswa

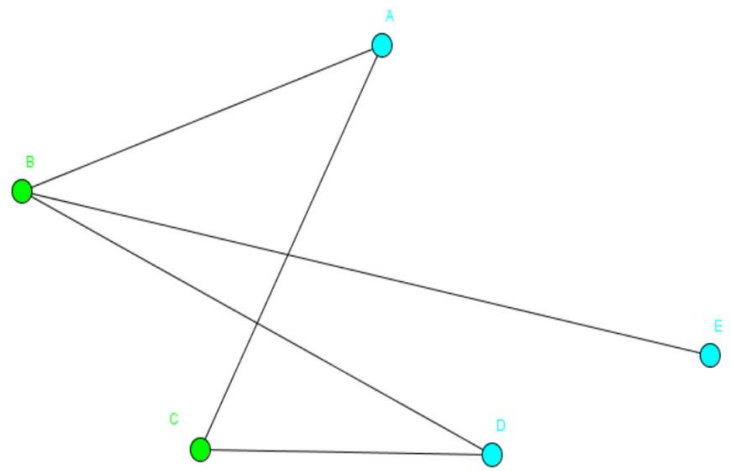

Gambar 3. Hasil Pewarnaan pada Simpul-Simpul Graf.

Dari gambar diatas diperoleh kesimpulan sebagai berikut:

1) Bilangan kromatik graf pada gambar diatas adalah

2) Sehingga, ujian mata kuliah $A, E$, dan $D$ dapat dilaksanakan bersamaan, sedangkan ujian mata kuliah $B$ dan $C$ dilakukan bersamaan tetapi pada waktu yang berbeda dengan mata kuliah $A, E$, dan $D$. 


\section{Hasil Penelitian dan Pembahasan}

Sistem penjadwalan perkuliahan yang dilakukan pada program studi Pendidikan Matematika FKIP Universitas Muslim Maros semester genap 2020/2021, terdapat 31 mata kuliah dengan 14 dosen pengampuh mata kuliah dan 17 ruangan yang dapat digunakan pada hari senin-kamis dengan kapasitas maksimal 40 orang. Secara lebih jelas disajikan dalam tabeltabel dibawah ini:

Tabel 2. Distribusi Mata Kuliah Semester Genap

\begin{tabular}{|c|c|c|c|}
\hline $\begin{array}{l}\text { Kode } \\
\text { MK }\end{array}$ & Mata Kuliah & $\begin{array}{c}\text { Kode } \\
\text { Dosen }\end{array}$ & Dosen Pengampuh Mata Kuliah \\
\hline \multicolumn{4}{|c|}{ Semester II } \\
\hline A1 & Studi Islam II (Islam dan Hukum- Hukumnya) & $\mathrm{NH}$ & Nasrul Hidayat, Lc.,M.Thi \\
\hline A2 & Ilmu Lingkungan dan Kearifan Lokal & PIL & Pertiwi Indah Lestari, S.Pd.,M.Pd. \\
\hline A3 & Aplikasi Komputer & $\mathrm{MN}$ & A.Muhajir Nasir, S.Pd.,M.Pd \\
\hline A4 & Perkembangan Peserta Didik & SS & Syamsuriyawati, S.Pd.,M.Pd \\
\hline A5 & Belajar dan Pembelajaran & RH & Rahmawati, S.Pd.,M.Pd \\
\hline A6 & Statistik Dasar & EW & Ernawati, S.Pd.,M.Pd \\
\hline A7 & Aljabar Elementer & $\mathrm{KR}$ & Khaerani, S.Pd.,M.Pd \\
\hline A8 & Kalkulus II & $\mathrm{BD}$ & Drs. Burhanuddin, M.Pd \\
\hline A9 & Geometri Dasar & $\mathrm{NF}$ & Nirfayanti, S.Si.,M.Pd. \\
\hline \multicolumn{4}{|c|}{ Semester IV } \\
\hline B1 & $\begin{array}{l}\text { Studi Islam IV (Masyarakat dan Kebudayaan } \\
\text { Islam) }\end{array}$ & MY & $\begin{array}{l}\text { Andi Muhammad Yusri, S.Ag., } \\
\text { M.Pd. }\end{array}$ \\
\hline $\mathrm{B} 2$ & Persamaan Diferensial Biasa & RH & Rahmawati, S.Pd., M.Pd \\
\hline B3 & Aljabar Linear II & KR & Khaerani, S.Pd.,M.Pd \\
\hline B4 & Geometri Analitik Ruang & NF & Nirfayanti, S.Si., M.Pd \\
\hline B5 & Teori Bilangan & DS & Dedy Setyawan, S.Pd., M.Pd \\
\hline B6 & Komputasi Matematika & SS & Syamsuriyawati, S.Pd., M.Pd \\
\hline B7 & Strategi Belajar Mengajar Matematika & DS & Dedy Setyawan, S.Pd., M.Pd \\
\hline $\mathrm{B} 8$ & Metode Numerik & KR & Khaerani, S.Pd.,M.Pd \\
\hline \multicolumn{4}{|c|}{ Semester VI } \\
\hline $\mathrm{C} 1$ & Penulisan Karya Ilmiah & KR & Khaerani, S.Pd.,M.Pd \\
\hline $\mathrm{C} 2$ & Micro Teaching & SS & Syamsuriyawati, S.Pd., M.Pd \\
\hline C3 & Islam dan Pendidikan & MS & Mastur, S.Ag., M.Pd \\
\hline $\mathrm{C} 4$ & Struktur Aljabar & SS & Syamsuriyawati, S.Pd., M.Pd \\
\hline $\mathrm{C} 5$ & Analisa Real II & $\mathrm{NF}$ & Nirfayanti, S.Si., M.Pd \\
\hline C6 & Geometri Transformasi & DS & Dedy Setyawan, S.Pd., M.Pd \\
\hline $\mathrm{C} 7$ & Teori Peluang & MN & A. Muhajir Nasir, S.Pd., M.Pd \\
\hline $\mathrm{C} 8$ & $\begin{array}{l}\text { Evaluasi Proses dan Hasil Pembelajaran } \\
\text { Matematika }\end{array}$ & EW & Ernawati, S.Pd., M.Pd \\
\hline C9 & Metodologi Penelitian Pendidikan Matematika & $\mathrm{NF}$ & Nirfayanti, S.Si.,M.Pd. \\
\hline \multicolumn{4}{|c|}{ Semester VIII } \\
\hline & Skripsi & & Tim \\
\hline D1 & Studi Islam 8 & NA & Nur Aliyah, S.Ag., M.Pd \\
\hline D2 & Workshop Pendidikan Matematika & EW & Ernawati, S.Pd., M.Pd \\
\hline \multicolumn{4}{|c|}{ Mata Kuliah Pilihan } \\
\hline $\mathrm{B} / \mathrm{C} / \mathrm{D}$ & Program Linear )* & $\mathrm{NF}$ & Nirfayanti, S.Si.,M.Pd. \\
\hline B9 & Sosiologi Pendidikan )* & $\mathrm{KH}$ & Dra.Hj.Khaeriyah, M.Si \\
\hline $\mathrm{B} / \mathrm{C} / \mathrm{D}$ & Telaah Matematika SMA)* & EW & Ernawati, S.Pd., M.Pd \\
\hline $\mathrm{C} 10$ & Teori Graph )* & $\mathrm{MN}$ & A. Muhajir Nasir, S.Pd., M.Pd \\
\hline $\mathrm{B} / \mathrm{C} / \mathrm{D}$ & Filsafat Pendidikan Matematika )* & RH & Rahmawati, S.Pd., M.Pd \\
\hline $\mathrm{B} / \mathrm{C} / \mathrm{D}$ & Bahasa Arab )* & MS & Mastur, S.Ag., M.Pd \\
\hline D3 & Manajemen Pendidikan)* & $\mathrm{RH}$ & Rahmawati, S.Pd., M.Pd \\
\hline
\end{tabular}


Tabel 3. Mata Kuliah tiap Tingkat Angkatan Mahasiswa

\begin{tabular}{ccc}
\hline No & Tingkat Mahasiswa & Banyaknya Mata Kuliah \\
1 & I & 9 \\
2 & II & 9 \\
3 & III & 10 \\
4 & IV & 3 \\
\hline
\end{tabular}

Berdasarkan aturan dari ketua Program Studi Pendidikan Matematika FKIP Universitas Muslim Maros, bahwa setiap mahasiswa tingkat II, III, dan IV diwajibkan menambah atau memprogramkan minimal satu mata kuliah pilihan. Maka pada tabel 3 setiap tingkatan semester tersebut ditambahkan satu mata kuliah pilihan, sehingga menghasilkan distribusi mata kuliah tiap tingkatan mahasiswa seperti pada tabel berikut

Tabel 4. Mata Kuliah yang Diprogramkan oleh tiap Tingkat Mahasiswa

\begin{tabular}{|c|c|c|c|c|c|c|c|c|c|c|c|c|c|c|c|c|c|c|c|c|c|c|c|c|c|c|c|c|c|c|}
\hline \multirow{2}{*}{$\begin{array}{c}\text { TK } \\
\text { Mhs }\end{array}$} & \multicolumn{30}{|c|}{ Mata Kuliah } \\
\hline & A1 & A2 & $\mathrm{A} 3$ & A4 & A5 & A6 & A7 & A8 & A9 & B1 & B2 & B3 & B4 & B5 & B6 & B7 & B8 & B9 & $\mathrm{C} 1$ & $\mathrm{C} 2 \mathrm{C} 3$ & $3 \mathrm{C} 4$ & $\mathrm{C} 5$ & $\mathrm{C} 6$ & $\mathrm{C} 7 \mathrm{C}$ & $\mathrm{C} 8$ & $\mathrm{C} 9$ & $\mathrm{C} 10 \mathrm{D}$ & D1 I & $\mathrm{D} 2 \mathrm{I}$ & D3 \\
\hline I & 1 & 1 & 1 & 1 & 1 & 1 & 1 & 1 & 1 & & & & & & & & & & & & & & & & & & & & & \\
\hline II & & & & & & & & & & 1 & 1 & 1 & 1 & 1 & 1 & 1 & 1 & 1 & & & & & & & & & & & & \\
\hline III & & & & & & & & & & & & & & & & & & & 1 & $\begin{array}{ll}1 & 1\end{array}$ & 1 & 1 & 1 & 1 & 1 & 1 & 1 & & & \\
\hline IV & & & & & & & & 1 & & & & & & & & 1 & 1 & & & & & & & & & & & 1 & 1 & 1 \\
\hline
\end{tabular}

Keterangan:

Angka 1 menunjukkan bahwa tingkat mahasiswa tersebut memprogramkan satu mata kuliah.

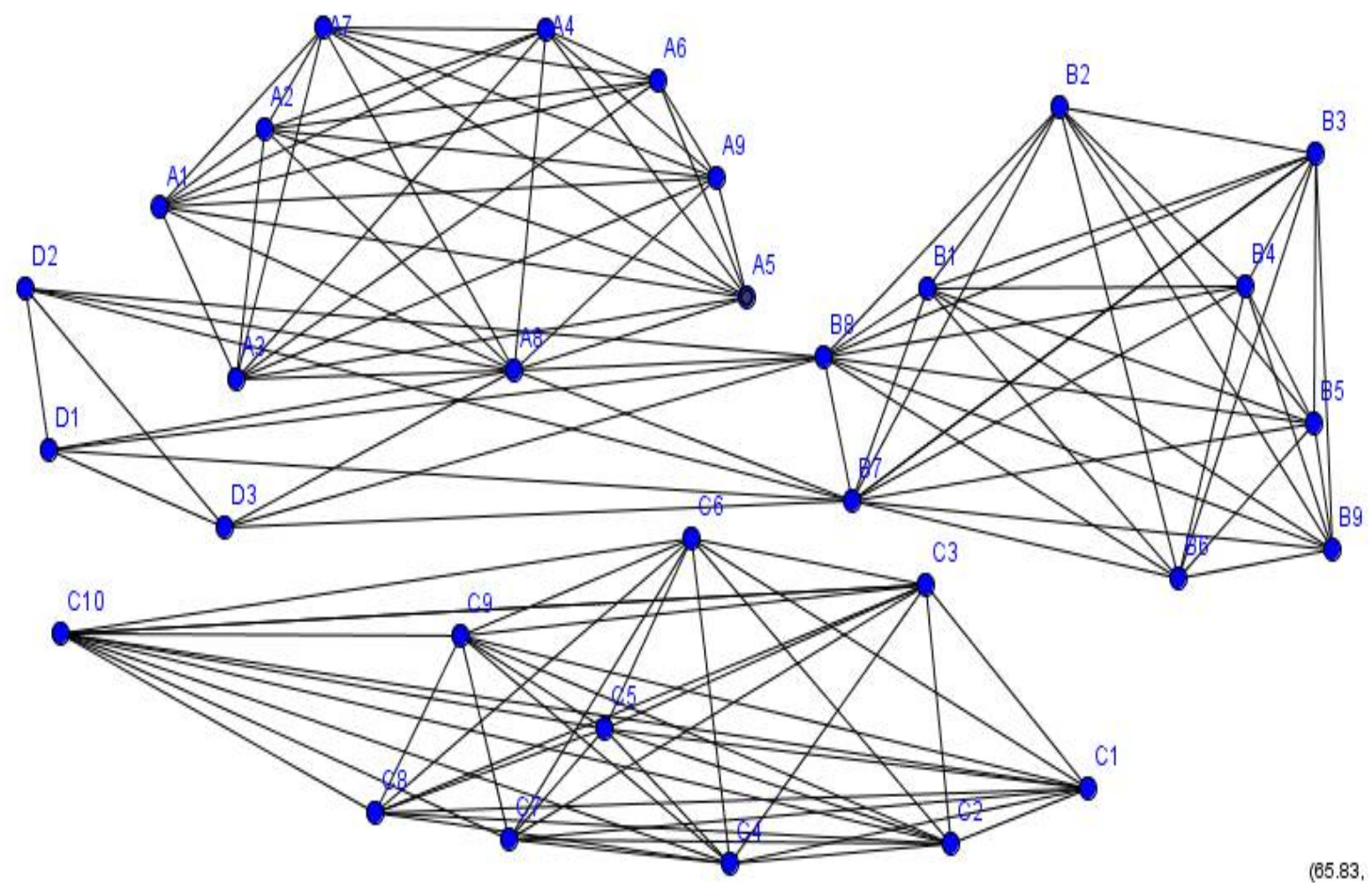

Gambar 4. Graf yang Menunjukkan Pemrograman Mata Kuliah dengan Ada Tingkatan Mahasiswa Tingkat Atas yang Memprogramkan Mata Kuliah Ditingkat Bawah. 
Tabel 5. Simpul Bertetangga dari Gambar Graf 4

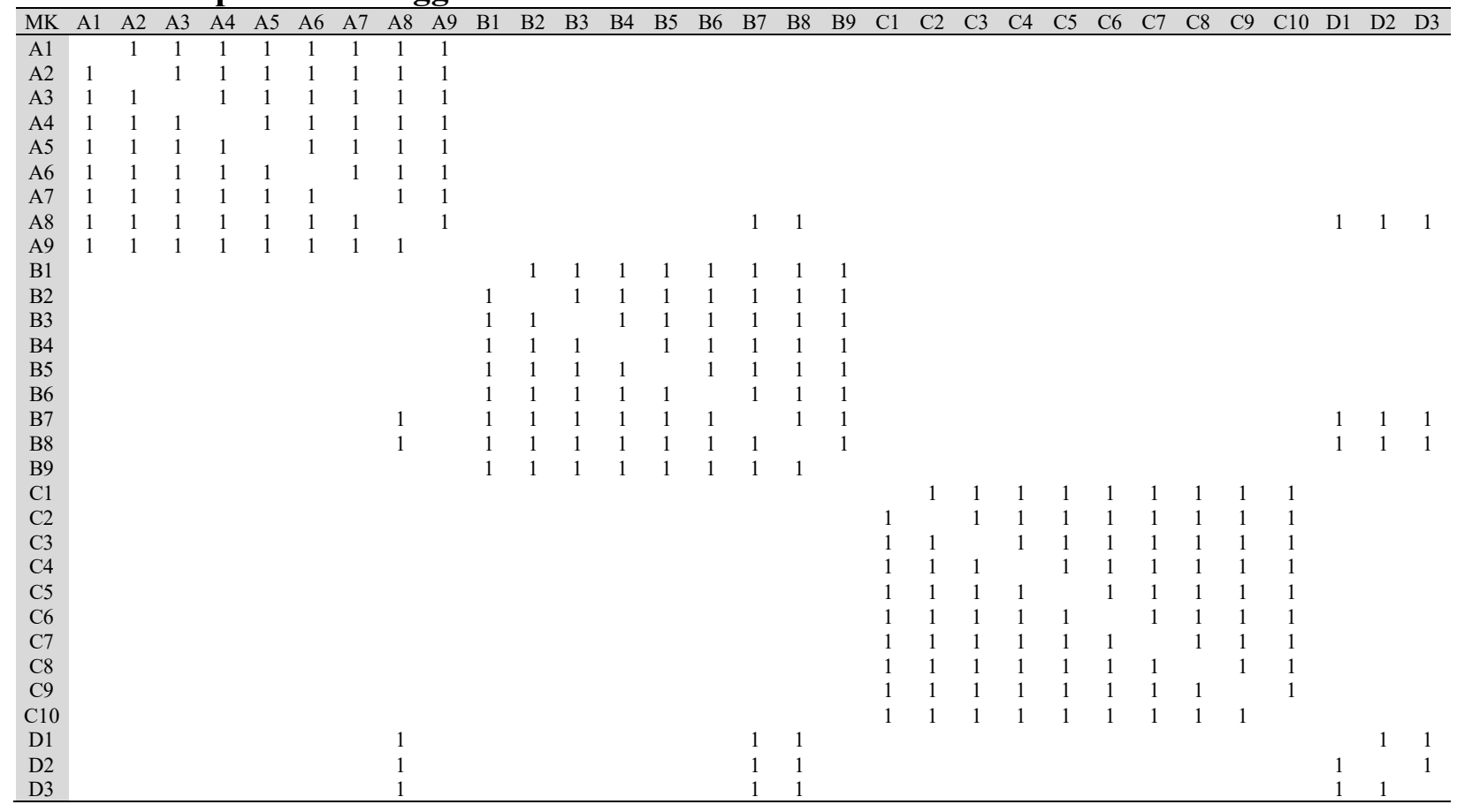

Tabel 6. Pewarnaan Graf Berdasarkan Algoritma Welch-Powell

\begin{tabular}{ccccccccccccccccccccccccccccccccccccc}
\hline Urutan & 1 & 2 & 3 & 4 & 5 & 6 & 7 & 8 & 9 & 10 & 11 & 12 & 13 & 14 & 15 & 16 & 17 & 18 & 19 & 20 & 21 & 22 & 23 & 24 & 25 & 26 & 27 & 28 & 29 & 30 & 31 \\
\hline Simpul & 8 & 16 & 17 & 19 & 20 & 21 & 22 & 23 & 24 & 25 & 26 & 27 & 28 & 1 & 2 & 3 & 4 & 5 & 6 & 7 & 9 & 10 & 11 & 12 & 13 & 14 & 15 & 18 & 29 & 30 & 31 \\
MK & A 8 & B7 & B 8 & C1 & C2 & C3 & C4 & C5 & C6 & C7 & C8 & C9 & C10 & A1 & A2 & A3 & A4 & A5 & A6 & A7 & A9 & B1 & B2 & B3 & B4 & B5 & B6 & B9 & D1 & D2 & D3 \\
Derajat & 13 & 12 & 12 & 9 & 9 & 9 & 9 & 9 & 9 & 9 & 9 & 9 & 9 & 8 & 8 & 8 & 8 & 8 & 8 & 8 & 8 & 8 & 8 & 8 & 8 & 8 & 8 & 8 & 5 & 5 & 5 \\
Warna & $\mathrm{a}$ & $\mathrm{b}$ & $\mathrm{c}$ & $\mathrm{a}$ & $\mathrm{b}$ & $\mathrm{c}$ & $\mathrm{d}$ & $\mathrm{e}$ & $\mathrm{f}$ & $\mathrm{g}$ & $\mathrm{h}$ & $\mathrm{i}$ & $\mathrm{j}$ & $\mathrm{b}$ & $\mathrm{c}$ & $\mathrm{d}$ & $\mathrm{e}$ & $\mathrm{f}$ & $\mathrm{g}$ & $\mathrm{h}$ & $\mathrm{i}$ & $\mathrm{a}$ & $\mathrm{d}$ & $\mathrm{e}$ & $\mathrm{f}$ & $\mathrm{g}$ & $\mathrm{h}$ & $\mathrm{i}$ & $\mathrm{j}$ & $\mathrm{d}$ & $\mathrm{e}$ \\
\hline
\end{tabular}

Tabel 7. Mata Kuliah yang Dapat Diadakan Secara Bersamaan

\begin{tabular}{llllllllllllllllllllllllllllllll}
\hline Simpul & 8 & 19 & 10 & 16 & 20 & 1 & 17 & 21 & 2 & 22 & 3 & 11 & 30 & 23 & 4 & 12 & 31 & 24 & 5 & 13 & 25 & 6 & 14 & 26 & 7 & 15 & 27 & 9 & 18 & 28 & 29
\end{tabular}

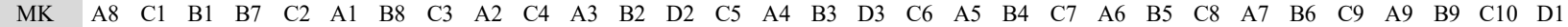

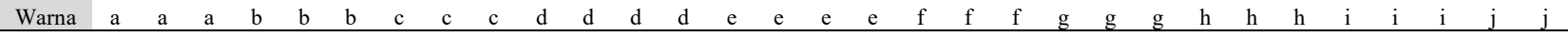

Tabel 8. Keterangan Pengkodean Warna

\begin{tabular}{cccccc}
\hline Kode & Warna & Kode & Warna & Kode & Warna \\
\hline a & Merah & e & Biru Muda & i & Cokelat \\
\hline b & Kuning & f & Ungu & j & Emas \\
\hline c & Hijau & g & Abu-abu & & \\
\cline { 1 - 3 } d & Pink & h & Biru Tua & & \\
\cline { 1 - 2 }
\end{tabular}




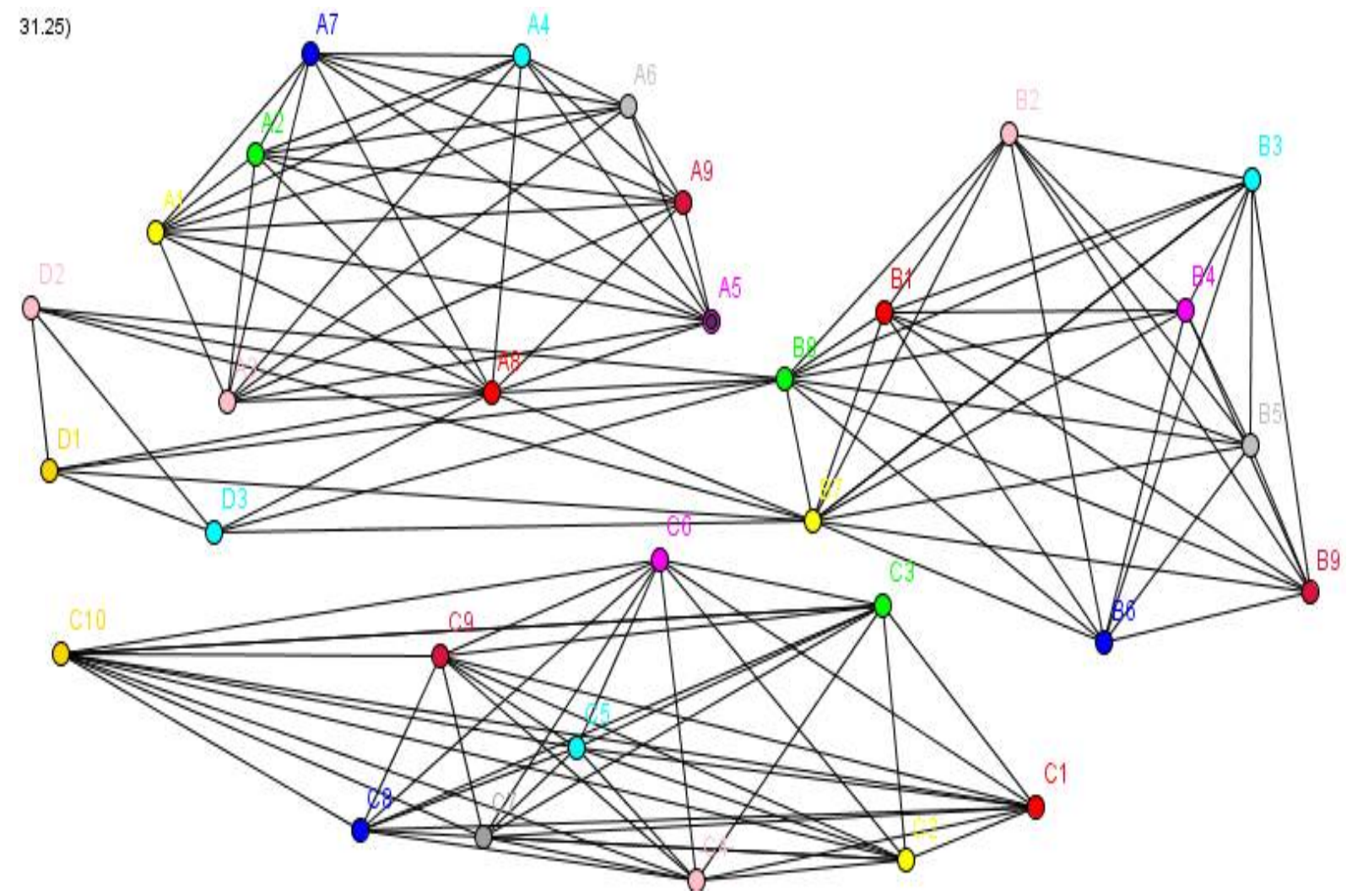

Gambar 5. Graf yang Telah Diwarnai Berdasarkan Algoritma Welch-Powell

Tabel 9. Contoh Penjadwalan yang Dihasilkan

\begin{tabular}{cccccccccccccc}
\hline \multirow{2}{*}{ Slot Waktu } & \multicolumn{3}{c}{ Senin } & \multicolumn{4}{c}{ Selasa } & \multicolumn{1}{c}{ Rabu } & \multicolumn{3}{c}{ Kamis } \\
\cline { 2 - 13 } & R1 & R2 & R3 & R1 & R2 & R3 & R4 & R1 & R2 & R3 & R1 & R2 & R3 \\
\hline T1 & A8 & B1 & C1 & C4 & A3 & B2 & D2 & C6 & A5 & B4 & C9 & A9 & B9 \\
T2 & B7 & C2 & A1 & C5 & A4 & B3 & D3 & C7 & A6 & B5 & C10 & D1 & - \\
T3 & B8 & C3 & A2 & - & - & - & & C8 & A7 & B6 & - & - & - \\
\hline
\end{tabular}

\section{Keterangan:}

$\mathrm{T} 1$ : jam pelajaran pertama, misalnya $13.30-14.00$

$\mathrm{T} 2$ : jam pelajaran kedua, misalnya $14.05-15.35$

T3 : jam pelajaran ketiga, misalnya $15.50-17.20$

$\mathrm{R} 1$ : ruang kuliah 1 , misalnya ruangan $\mathrm{A}$

$\mathrm{R} 2$ : ruang kuliah 2, misalnya ruangan $\mathrm{B}$

$\mathrm{R} 3$ : ruang kuliah 3 , misalnya ruangan $\mathrm{C}$

$\mathrm{R} 4$ : ruang kuliah 4 , misalnya ruangan $\mathrm{D}$

Permasalahan penyusunan jadwal perkuliahan dihadapkan dengan beberapa batasan komponen-komponen terkait, antara lain mata kuliah, mahasiswa, dosen, ruang kuliah dan waktu yang tersedia. Pada penelitian awal ini, komponen yang dipertimbangkan adalah mata kuliah dan banyaknya mahasiswa. Sebagai studi kasus, jadwal perkuliahan yang ditinjau adalah jadwal pada program studi Pendidikan Matematika FKIP Universitas Muslim Maros. Pada program studi Pendidikan Matematika Tahun Akademik 2020/2021 semester genap, mata kuliah tiap tingkat angkatan mahasiswa dirangkum pada tabel 3. Jadwal perkuliahan yang ditinjau adalah jadwal perkuliahan setiap tingkat dengan terdapat mahasiswa tingkat atas yang mengambil mata kuliah ke tingkat bawah. Kondisi yang merepresentasikan kasus ini ditunjukkan pada tabel 4 . 
Permasalahan yang ditinjau adalah terdapat mahasiswa yang mengambil beberapa mata kuliah secara bersamaan. Hal ini mengakibatkan terdapat kemungkinan mahasiswa tidak dapat mengikuti semua kelas yang dikontraknya karena terdapat kesamaan jadwal beberapa mata kuliah yang diprogramkannya. Oleh karena itu, data mata kuliah yang diikuti tiap tingkat mahasiswa dinyatakan dalam bentuk graf, yaitu mata kuliah dinyatakan sebagai simpul-simpul graf dan hubungan mata kuliah yang diprogramkan secara bersamaan oleh mahasiswa dinyatakan sebagai sisi graf. Jika terdapat dua mata kuliah yang diikuti oleh mahasiswa yang sama, mata kuliah tersebut akan dihubungkan oleh sisi. Hal ini bertujuan agar setiap jadwal tidak bentrok. Seperti yang ditunjukan tabel 4, misalkan terdapat mahasiswa tingkat IV yang memprogramkan mata kuliah A8 ditingkat I dan mata kuliah B7 serta B8 ditingkat II, maka mata kuliah A8 dan B7/B8 serta mata kuliah yang ada ditingkat IV tidak boleh diselengggarakan secara bersamaan.

Agar lebih mudah dalam menganalisis, dibuat tabel simpul-simpul bertetangga. Untuk kasus di atas, penjadwalan ditunjukkan seperti tabel 5. Setelah menyajikan tabel bertetangga, maka untuk menentukan pewarnaan simpul, digunakan algoritma welch-powell, yaitu mengurutkan simpul-simpul pada graf dalam derajat yang menurun kemudian menggunakan satu warna untuk mewarnai simpul pertama (yang mempunyai derajat paling tinggi) dan simpul yang lain (sesuai dengan urutannya) yang tidak bertetangga dengan simpul yang pertama ini.

Untuk kasus tersebut, pewarnaan graf ditunjukkan oleh tabel 6. Dari tabel tersebut diperoleh bilangan kromatik untuk kasus tersebut adalah 10. Pada kasus ini terdapat mahasiswa tingkat IV yang memprogramkan mata kuliah A8 ditingkat I dan mata kuliah B7 serta B8 ditingkat II, seperti ditunjukkan tabel 4. Beberapa mata kuliah dapat dilaksanakan secara bersamaan, diantaranya yang pertama $\mathrm{A} 8, \mathrm{~B} 1$ dan $\mathrm{C} 1$, yang kedua $\mathrm{B} 7, \mathrm{C} 2$ dan $\mathrm{A} 1$, yang ketiga B8, C3 dan A2, dan seterusnya. Lebih lengkap ditunjukkan ditunjukkan tabel 7. Hasil penerapan algoritma welch-powell, secara umum diperoleh bahwa penyusunan jadwal mata kuliah tingkat IV yang berlabel D tidak boleh disatukan dengan mata kuliah tingkat I dan II yang berlabel A8 dan B7 serta B8.

Penerapan algoritma welch-powell menghasilkan pewarnaan simpul graf sehingga simpul-simpul yang bertetangga diwarnai dengan warna berbeda. Pewarnaan simpul graf untuk kasus ini ditunjukkan oleh gambar 5. Warna yang sama menunjukkan bahwa mata kuliah tersebut dapat disusun secara bersamaan. Terdapat 10 warna untuk mewarnai graf pada kasus di tabel 6, artinya terdapat 10 sesi perkuliahan berbeda yang harus disiapkan untuk menyusun jadwal perkuliahan tersebut sehingga tidak terjadi bentrok. Untuk mengatasi permasalahan ini, digunakan metode pewarnaan simpul untuk mengetahui besar bilangan kromatiknya. Bilangan kromatik ini kemudian digunakan untuk mengetahui jumlah minimum sesi perkuliahan berbeda yang diperlukan, sehingga seluruh mahasiswa dapat mengikuti kelas dengan baik tanpa ada jadwal yang bentrok. Gambar 5 menunjukkan graf untuk kasus di atas.

Pada penelitian ini semua mata kuliah yang berbeda yang memiliki warna sama berdasarkaan pewarnaan algoritma welch-powel akan dijadwalkan pada hari dan waktu yang sama serta tentunya dengan ruangan yang berbeda. Pada kasus diatas ruang kuliah tidak menjadi masalah karena ruang kuliah yang tersedia sangat memadai jumlahnya, sedangkan kebutuhan ruang kuliah perhari maksimal 11 dan minimal 4 ruangan. Salah satu opsi penjadwalan ditunjukkan oleh tabel 9. Beberapa batasan yang dipertimbangkan dalam penelitian ini adalah mata kuliah dalam semester yang sama tidak dijadwalkan pada slot waktu yang sama, mata kuliah pada semester yang sama dijadwalkan maksimal 3 kali perhari dan waktu perkuliahan maksimal sampai pukul 17.30 selama 4 hari perkuliahan.

Hasil penelitian disajikan dalam bentuk tabel, gambar atau deskriptif. Analisis dan interpretasi hasil ini diperlukan sebelum dibahas. Pembahasan difokuskan pada pengaitan data dan hasil analisisnya dengan permasalahan atau tujuan penelitian dan konteks teoritis yang lebih luas. Penyusunan jadwal perkuliahan secara manual dianggap kurang efisien karena seringkali 
terjadi konflik atau bentrok mata kuliah atau ruang kuliah pada slot waktu tertentu. Hal ini dapat disebabkan oleh adanya penggunaan ruangan yang sama untuk mata kuliah yang berbeda, adanya adanya dosen pengajar pada mata kuliah yang berbeda, terbatasnya ruang kuliah dan adanya tingkatan mahasiswa yang mengambil mata kuliah di tingkat bawah atau atas. Setelah diterapkan teori pewarnaan graf dengan algoritma Welch-Powell tidak terjadi lagi mata kuliah yang bentrok sehingga, penjadwalan menjadi lebih optimal.

Penerapan teori pewarnaan graf ini menghasilkan penyusunan jadwal yang lebih jelas dan terstruktur, karena dapat diketahui mata kuliah yang dapat dijadwalkan secara bersamaan dan banyaknya sesi perkuliahan yang dibutuhkan secara minimal. Namun pada penelitian ini masih banyak batasan lain yang belum dipertimbangkan, seperti kesediaan dosen untuk mengajar pada waktu dan hari tertentu, alokasi mata kuliah yang akan diajarkan dosen dan lain sebagainya. Oleh karena itu batasan-batasan seperti diatas perlu diperhatikan agar penjadwalan dapat jauh lebih optimal.

Berdasarkan hasil penelitian yang telah dilakukan sebelumnya oleh Sunarni, et al. (2018) di Fakultas Sains dan Teknologi Universitas Katolik Musi Informatika serta penelitian yang telah dilakukan oleh Daswa \& Riyadi (2017) di program studi Pendidikan Matematika FKIP Universitas Kuningan, ternyata sesuai dengan hasil penelitian yang dilakukan diatas. Bahwa dengan menerapkan teori pewarnaan graf dengan algoritma Welch-Powell dapat menghasilkan sistem penjadwal yang lebih optimal.

\section{Kesimpulan}

Berdasarkan hasil analisis data dan pembahasan yang telah dilakukan pada bab IV, maka peneliti menarik beberapa simpulan dari hasil penelitian tersebut sebagai berikut:

1. Penyusunan jadwal perkuliahan dapat dioptimalkan dengan menerapkan pewarnaan simpul graf dengan algoritma Welch-Powell, sehingga tidak terjadi jadwal mata kuliah yang bentrok.

2. Permasalahan utama dalam penyusunan jadwal perkuliahan adalah ketika ada mahasiswa tingkat bawah yang mengambil mata kuliah ditingkat atas atau sebaliknya.

\section{DAFTAR PUSTAKA}

Al-Mouhamed, M., \& Dandashi, A. (2010). Graph Coloring for Class Scheduling. IEEE/ACS Internation Conference on Computer Systems and Applications (AICCSA), 1-4.

Astuti, S. (2011). Penyusunan Jadwal Ujian Mata Kuliah Dengan Algoritma Pewarnaan Graf Welch Powell. Jurnal Dian, 11(1).

Bozyer, Z., Basar, M. S., \& Aytekin, A. (2011). A Novel Approach of Graph Coloring for Solving University Course Timetabling Problem. The Second International Symposium on Computing in Science \& Engineering, 560-566.

Buliali, J. L., Herumurti, D., \& Wiriapradja, G. (2008). Penjadwalan Matakuliah Dengan Menggunakan Algoritma Genetika dan Metode Constraint Satisfaction. Jurnal Ilmiah Teknologi Informasi, 7(1), 29-38.

Daswa, D., \& Riyadi, M. (2017). Aplikasi Pewarnaan graf pada Masalah Penyusunan Jadwal Perkuliahan di Universitas Kuningan. Jurnal Edukasi Dan Sains Matematika (JES-MAT), $3(2), 217-226$. 
Dewi, F. K. S. (2014). Pembangunan Perangkat Lunak Pembangkit Jadwal Kuliah dan Ujian Dengan Metode Pewarnaan Graf. Buana Informatika, 1(1), 57-68.

Hiryanto, L., \& Thio, J. S. (2011). Pengembangan Metode Graph Coloring untuk university Course Timetabling Problem pada Fakultas Teknologi Informasi Universitas Tarumanagara. Jurnal Ilmu Komputer Dan Informasi, 4(2), 82-91.

Jat, S. N., \& Yang, S. (2008). A Memetic Algorithm for the University Course Timetabling Problem. IEEE International Conference on Tools with Artificial Intelligence, 427-433.

Kohshori, M. S., \& Abadeh, M. S. (2012). Hybrid Genetic Algorithms for University Course Timetabling. International Journal of Computer Science Issues, 9(2), 446-455.

Li, J., Burke, E. K., Curtois, T., Petrovic, S., \& Qu, R. (2012). The Falling Tide Algorithm: A New Multi-Objective Approach for Complex Workforce Scheduling. Omega, 40(3), 283293.

Lumbantoruan, I. (2014). Perancangan Aplikasi Penjadwalan Bimbingan Belajar Dina Education Center Menggunakan Metode Welch Powell. Pelita Informatika Budi Darma, $7(2), 141-146$.

Malkawi, M., Hassan, M. A.-H., \& Hassan, O. A.-H. (2008). A New Exam Scheduling Algorithm Using Graph Coloring. The International Arab Journal of Information Technology, 5(1), 80-87.

Munir, R. (2014). Matematika Diskrit Revisi Kelima. Bandung: Penerbit Informatika.

Purwanto. (2010). Matematika Diskrit. Malang: IKIP Malang.

Puspaningrum, W. A., Djunaidy, A., \& Vinarti, R. A. (2013). Penjadwalan Mata Kuliah Menggunakan Algoritma Genetik di Jurusan Sistem Informasi ITS. Jurnal Teknik POMITS, 2(1), 127-131.

Sabar, N. R., Ayob, M., Kendall, G., \& Qu, R. (2012). A Honey Bee Mating Optimization Algorithm for Educational Timetabling Problems. European Journal of Operatorin Research, 216(3), 533-543.

Sabar, N. R., Ayob, M., Kendall, G., \& Qu, R. (2009). Roulette Wheel Graph Colouring for Solving Examination Timetabling Problems. Third International Conference, COCOA 2009, 463-470.

Saragih, H., Hoendarto, G., Reza, B., \& Setiyadi, D. (2012). Aplikasi Sistem Perangkat Lunak Menggunakan Algoritma Ant Untuk Mengatur Pendjadwalan Kuliah. Jurnal Teknik Dan Ilmu Komputer, 1(3), 241-256.

Setemen, K. (2010). Implementasi Algoritma Genetika Dalam Pengembangan Sistem Aplikasi Penjadwalan Kuliah. Jurnal IKA, 8(1), 56-68.

Setiawati, F., Noviani, E., \& Prihandono, B. (2015). Pewarnaan Sisi Graf Bipartit Untuk Penjadwalan Kuliah. Bimaster, 4(1), 69-76. 
Siswono, T., \& Palgunadi, S. (2014). Analisa Kombinasi Algoritma Genetika Dengan Algoritma Palgunadi Untuk Penjadwalan Mata Kuliah Di Universitas Sebelas Maret. Prosiding Seminar Nasional Sains Dan Teknologi, 50-55.

Sunarni, T., Bendi, R., \& Alfian, A. (2018). Penerapan Teknik Pewarnaan Simpul Graf Pada Permasalahan Penjadwalan Kuliah. Prosiding Ritektra, 8(1), 84-91.

Susiloputro, A., Rochmad, R., \& Alamsyah, A. (2012). Penerapan Pewarnaan Graf pada Penjadwalan Ujian menggunakan Algoritmawelsh Powell. UNNES Journal of Mathematics, 1(1), 1-7.

Tasari. (2012). Aplikasi Pewarnaan Graf Pada Penjadwalan Perkuliahan di Program Studi Pendidikan Matematika Unwidha Klaten. MAGISTRA, 24(82), 70-78.

Wijaya, A. (2009). Matematika Diskrit. Bandung: Politeknik Telkom.

Yudihartanti, Y., Syukur, A., \& Wahono, R. S. (2011). Analisis Komparasi Metode Mamdani dan Sugeno dalam Penjadwalan Mata Kuliah. Jurnal Teknologi Informasi, 7(2), 109-116. 